Illinois State University

ISU ReD: Research and eData

Theses and Dissertations

3-30-2021

\title{
"I Thought That We Could Nurture The Nature Out Of Our Son": Making Meaning Of Parenting In The Narratives Of Parents Of Children In Residential Treatment
}

Jared V. Worwood

Illinois State University, jvworwood@gmail.com

Follow this and additional works at: https://ir.library.illinoisstate.edu/etd

Part of the Communication Commons, and the Family, Life Course, and Society Commons

\section{Recommended Citation}

Worwood, Jared V., "'I Thought That We Could Nurture The Nature Out Of Our Son": Making Meaning Of Parenting In The Narratives Of Parents Of Children In Residential Treatment" (2021). Theses and Dissertations. 1420.

https://ir.library.illinoisstate.edu/etd/1420

This Thesis is brought to you for free and open access by ISU ReD: Research and eData. It has been accepted for inclusion in Theses and Dissertations by an authorized administrator of ISU ReD: Research and eData. For more information, please contact ISUReD@ilstu.edu. 
"I THOUGHT THAT WE COULD NURTURE THE NATURE OUT OF OUR SON": MAKING MEANING OF PARENTING IN THE NARRATIVES OF PARENTS OF CHILDREN IN RESIDENTIAL TREATMENT

\section{JARED V. WORWOOD}

\section{Pages}

This study implements relational dialectics theory to explore the meaning of parenting from the perspective of parents who had enrolled a child in a residential treatment program. Contrapuntal analysis of six interviews revealed two discourses competing to make meaning of parenting. The Discourse of Demanding Parenting Ideals (DDPI) consisted of two themes: relentless sacrifice and complete responsibility, whereas themes of boundary-setting and acceptance compose the Discourse of Realistic Best Effort (DRBE). Discursive interplay between these discourses occurred in the forms of diachronic separation, synchronic interplay, and discursive transformation to make meaning of parenting and hold theoretical and practical implications.

KEYWORDS: relational dialectics theory, parent-child relationships, parenting, residential treatment, mental health 
"I THOUGHT THAT WE COULD NURTURE THE NATURE OUT OF OUR SON": MAKING MEANING OF PARENTING IN THE NARRATIVES OF PARENTS OF CHILDREN IN RESIDENTIAL TREATMENT

\author{
JARED V. WORWOOD
}

\author{
A Thesis Submitted in Partial \\ Fulfillment of the Requirements \\ for the Degree of \\ MASTER OF SCIENCE \\ School of Communication \\ ILLINOIS STATE UNIVERSITY
}


(C) 2021 Jared V. Worwood 
“I THOUGHT THAT WE COULD NURTURE THE NATURE OUT OF OUR SON": MAKING MEANING OF PARENTING IN THE NARRATIVES OF PARENTS OF CHILDREN IN RESIDENTIAL TREATMENT

\author{
JARED V. WORWOOD
}

COMMITTEE MEMBERS:

Lindsey J. Thomas, Chair

Aimee E. Miller-Ott

John R. Baldwin 


\section{ACKNOWLEDGMENTS}

First and foremost, I would like to thank my mother Leanne and my father Danny for truly being ideal parents (whatever that means). Our conversations were my first laboratory and remain my most productive think tank. I would also like to thank each of my siblings, Daniel, Kimber, and Jenna who have not only helped me reflect on how we are parented, but also show me creative and meaningful ways to parent as they raise their own children. All of your support throughout my academic career has helped me understand the importance of family research and conversely, the impact that family has on research. I also would like to thank Dr. Lindsey Thomas whose patience, good humor, and insightful questions pushed me out of my comfort zone while simultaneously helped me feel that I belonged in academia. It is still one of my life goals to run a hobby farm with you somewhere in rural Illinois. I would like to also thank Dr. Miller-Ott and Dr. Baldwin for their invaluable help as thesis committee members. Your thoughtful feedback helped me make meaningful revisions to my thesis, not to mention the fact that this whole project started out as a paper proposal for Dr. Miller-Ott's family communication class. I also owe a debt of gratitude to Dr. Scharp who was my undergraduate mentor at Utah State and continues to lead and guide me to this day. I think it also important to recognize the contributions of my participants. At the beginning of this project, I did not realize that I would be soliciting such vulnerable and honest accounts of some of the toughest moments in a person's life. I feel honored that each participant was willing to open up about their pain, uncertainties, and aspirations. I felt inspired by the lengths these parents went to help their children and themselves. Finally, I would like to thank my pigs, Clover and Rosie, whose grunts and squeals got me through a global pandemic and this thesis.

J. V.W. 


\section{CONTENTS}

Page

ACKNOWLEDGMENTS

i

CONTENTS

ii

CHAPTER I: INTRODUCTION 1

CHAPTER II: REVIEW OF LITERATURE 3

Mental (Un)Health and Family $\quad 3$

Residential Treatment 5

Mental (Un)Health and Family Stigma $\quad 8$

$\begin{array}{ll}\text { Disrupted Narratives of Parenting } & 10\end{array}$

$\begin{array}{ll}\text { Nature Versus Nurture } & 12\end{array}$

$\begin{array}{ll}\text { Parental Ambivalence } & 13\end{array}$

Theoretical Framework: Relational Dialectics Theory (RDT) 14

$\begin{array}{ll}\text { Overview of Present Study } & 17\end{array}$

$\begin{array}{ll}\text { Conclusion } & 18\end{array}$

$\begin{array}{ll}\text { CHAPTER III: METHODS } & 19\end{array}$

$\begin{array}{ll}\text { Participants } & 19\end{array}$

$\begin{array}{ll}\text { Data Collection } & 19\end{array}$

Data Analysis $\quad 21$

CHAPTER IV: FINDINGS 24

Discourse of Demanding Parenting Ideals $\quad 24$

Parents Sacrifice Without Limits 24 
Parents are Completely Responsible $\quad 26$

Discourse of Realistice Best Effort $\quad 29$

$\begin{array}{ll}\text { Parents Set Boundaries } & 30\end{array}$

$\begin{array}{ll}\text { Parents Accept } & 31\end{array}$

Discursive Interplay $\quad 34$

Diachronic Separation 35

$\begin{array}{ll}\text { Synchronic Interplay } & 37\end{array}$

Discurive Transformation $\quad 39$

$\begin{array}{ll}\text { Conclusion } & 41\end{array}$

CHAPTER V: DISCUSSION

Theoretical and Practical Implications 43

Limitations and Future Directions $\quad 49$

$\begin{array}{ll}\text { Author Positioning } & 50\end{array}$

$\begin{array}{ll}\text { Conclusion } & 51\end{array}$

REFERENCES

APPENDIX A: PARTICIPANT RESEARCH CALL 62

APPENDIX B: INFORMED CONSENT FORM

APPENDIX C: DEMOGRAPHIC QUESTIONNAIRE $\quad 67$

$\begin{array}{ll}\text { APPENDIX D: INTERVIEW PROTOCOL } & 70\end{array}$ 


\section{CHAPTER I: INTRODUCTION}

According to the Child Mind Institute, an estimated 17.1 million children in the United States have been diagnosed with a psychiatric disorder, and it is estimated that nearly one half of American youth will have a diagnosable mental illness before they are 18 (Children's Mental Health Report, 2015). Parents often find it difficult to provide for the emotional needs and safety of children with a severe behavioral disorder or mental illness and as a last recourse, might turn to a residential treatment center (RTC) for help (Frensch \& Cameron, 2002). RTCs are inpatient facilities where children can receive constant, professional psychiatric care (American Academy of Child and Adolescent Psychiatry [AACAP], 2010). These programs offer help for youth who suffer from moderate to severe emotional and behavioral disorders for which home and outpatient psychiatric services might not be sufficient (Preyde et al., 2009). RTCs are valuable resources for families and communities, as they provide interventions for youth with mental illness, as well as emotional and behavioral problems (Preyde et al., 2015).

Although RTCs are valuable resources, stigma associated with mental health and "poor" parenting is abundant surrounding the context of children, mental illness, and enrolling children in residential treatment (Corrigan \& Miller, 2004; Sayal, et al., 2010; Van Der Sanden et al., 2015). Stigma arises when parents are blamed for either causing or failing to fix a child's mental health (Corrigan \& Miller, 2004). Parents are also reluctant to place a child in residential treatment for fear of being labeled as unfit to parent (Sayal, et al., 2010; Tahhan et al., 2010). Despite this phenomenon, little research examines the cultural narratives that might operate to affirm or marginalize parents' experiences and/or encourage or dissuade families from working with RTCs. Instead, related research most often focuses on various family characteristics (e.g., Mark \& Buck, 2006; Preyde et al., 2011; Robst et al., 2014; Sunseri, 2004; Tahhan et al., 2010; 
Thomson et al., 2011). Understanding family characteristics and outcomes is an important step toward involving families in their child's residential treatment and addressing familial support post-treatment (Lieberman, 2009; Robst et al., 2014), yet it is not the only productive site of exploration. Because of the parental identity threats that parents who have enrolled their child in an RTC face, they must find ways of legitimizing themselves through communication to themselves and the community.

As parents communicate their parental experiences and decisions, their narratives become a site in which to explore (a) the ideologies at play in this context and (b) the ways in which parents struggle with and make sense of their experience with putting their child in residential treatment. Towards this end, the present study aims to illuminate cultural ideologies and parental experiences by examining the interviews of six parents who have enrolled a child in an RTC. Below, Chapter 2 reviews the related literature and theory, Chapter 3 describes the methodology for the study, Chapter 4 presents study findings, and Chapter 5 presents a discussion of the findings as related to existing literature and in light of possible future directions. 


\section{CHAPTER II: REVIEW OF LITERATURE}

Parents who enroll their child in a residential treatment center (RTC) must communicatively navigate the discourses of mental health and parenting to address the stigma they face from friends, family and in some cases, themselves, to legitimize their parenting decisions. To contextualize this struggle and explain how it will be studied, I first discuss the literature on child mental (un)health, the role that residential treatment plays, and how the child's mental (un)health and residential treatment might affect the family unit. Second, I consider how parents who put their children in residential treatment might violate cultural/life course narratives of parenting. Finally, I review the principles that inform the theoretical framework for the study, relational dialectics theory (RDT), and its corresponding method, contrapuntal analysis. Of note, although this discussion specifically focuses on how families face stigma and other complications due to their association with an individual with mental and/or behavioral health issues, mental and behavioral health issues are not a result of an intentional action of the individual, nor a moral shortcoming (Corrigan \& Miller, 2004). The purpose of this research is to bring attention to harmful narratives and systems that marginalize and harm families and individuals with issues surrounding mental and/or behavioral health.

\section{Mental (Un)Health and Family}

Psychiatric disorders are becoming increasingly common in children and adolescents from three to 17 years old (Children's Mental Health Report, 2015; Merikangas et al., 2009). Among the most common diagnoses are ADHD (9.4\% of children and adolescents), behavior problems (7.4\%), anxiety (7.1\%), and depression (3.2\%) (National Center for Health Statistics, 2020). Issues of mental or behavioral health disrupt family functioning, putting strain on familial relationships, emotional wellbeing, financial security, and feelings of efficacy (Yatchmenoff et 
al., 2004). Despite the disruption and strain, policymakers and mental-health professionals see the family home as the preferable setting for their child's treatment in conjunction with outpatient psychiatric services (Frensch \& Cameron, 2002). However, when a child's behavior or mental health needs exceed the care their family can provide, families might seek out (or be encouraged to seek out) an RTC to provide constant supervision and therapeutic treatment (Tahhan et al., 2010). As such, RTCs are positioned as helpful, yet last-resort, resources.

Because RTCs are seen as a last resort (Frensch \& Cameron, 2002; Tahhan et al., 2010), they usually host children who demonstrate extreme behavior (i.e., many children are introduced to RTCs only when they have begun to manifest extreme behaviors and other options have been exhausted). Many patients of RTCs have multiple psychiatric diagnoses that include conduct issues, depression, and anxiety (Connor et al., 2004). Although these diagnoses are perceived as relatively common and treatable outside of a residential setting (National Center for Health Statistics, 2020), a survey of several RTCs revealed that all youth (in the surveyed RTCs) had severe mental health problems ( $82 \%$ on psychotropic medication at the time of admission); nearly half of patients had histories of criminal activity; half of patients had histories of psychiatric hospitalization; a third of patients had histories of substance abuse and suicidal ideation; and $10 \%$ of patients had histories of sexual perpetration (Baker et al., 2007). Given that such issues of mental and emotional health can become unmanageable problems in school, community, and family settings, RTCs are a valuable resource to families and communities for their ability to provide constant, professional care for children, as well as decrease the strain on families and communities that might not be equipped to handle children with manifest multiple mental and behavioral challenges (Preyde et al., 2009; Stroul \& Friedman, 1996). 


\section{Residential Treatment}

RTCs provide several interventions for youth with emotional and behavioral problems who necessitate constant supervision and out-of-home placement (Preyde et al., 2015). Although all RTCs share commonalities such as out-of-home treatment and supervision, there is no current federal regulation of RTCs, and programs vary greatly in the range and intensity of services offered (Work Group on Healthcare Access and Economics, 2010). To increase their marketability and legitimacy, as well as to reduce risk, RTCs may become accredited through The Joint Commission by meeting their standards of behavioral health care (The Joint Commission, n.d.b). Such standards pertain to care practices, information management, safety, medication management, and individual rights (The Joint Commission, n.d.a). The American Academy of Child and Adolescent Psychiatry (AACAP) also developed guidelines that focus on areas of concern for RTCs that The Joint Commission's standards do not address (Work Group on Healthcare Access and Economics, 2010). According to AACAP, RTCs should:

- provide for the child's developmental, emotional, physical, and educational needs including intensive mental health care, physical health care, and access to ongoing education at the appropriate developmental level

- offer different modalities of evidence-based treatment specific to the child's psychiatric, educational, developmental, and medical disorders

- follow national guidelines for treatment for specific mental disorders.

- train staff in evidence-based psychosocial interventions

- train staff in the use of family-centered care 
- state what conditions they do and do not treat and the types of treatment they are able to provide

- have written policies covering significant events like injuries, elopements, restraints, as well as patient and/or family complaints (p. 3)

These guidelines often serve to differentiate RTCs from teen "bootcamps" or other types of "troubled teen" programs that rely more on a principle of tough love; rather than deliver constant and multidisciplinary therapeutic interventions (Golightly, 2020; Work Group on Healthcare Access and Economics, 2010).

However, despite the rigorous standards that RTC administration can adopt and enforce within their facility, and perceptions of RTCs as valuable community and family resources, it is hard to measure how successful residential treatment interventions are for their patients. Research suggests that residential treatment is helpful in that it can prevent harm to families and communities while simultaneously providing a therapeutic context to help address issues of behavioral or mental health (Goldberg, 1991). In a review of research on residential treatment, Bettmann and Jasperson (2009) found that there is evidence that RTCs help young patients change problematic behavior, aide in their social adaptation, and increase their family functioning. Even so, Bettman and Jasperson point out that there are large gaps in research concerning what types of treatment and the process by which they are administered lead to these successful outcomes. Despite these findings, Yeheskel (2020) states that the long-term successes of these studied residential treatment centers are hard to generalize and apply due to different measurements of success (e.g., educational outcomes, family integration, or symptom reduction) as well as the variability of socio-economic, geographic, familial, and symptomatic contexts of 
the patients that RTCs host. Yeheskel also states that no consistent construct of treatment success has been developed among practitioners or scholars.

Despite the research limitations of many RTC studies, recent research has revealed family involvement in RTCs consistently improves treatment outcomes during and after residential treatment (Sunseri, 2020). Correspondingly, in a meta-analysis of residential treatment research, Frensch and Cameron (2002) found that familial involvement in residential treatment was crucial to maintaining the emotional and behavioral progress of children after leaving an RTC.

Despite practitioners and researchers calling for more familial integration into treatment (Affronti \& Levison-Johnson, 2009; Sunseri, 2020; Work Group on Healthcare Access and Economics, 2010), surveys show that many RTCs still do not actively implement the family in treatment and in some cases actively limit their participation (Brown et al., 2010). Although RTCs might limit familial involvement due to complicated family situations such as abuse, abandonment, or a family's inability to support their child (Preyde et al., 2009; Van Der Sanden et al., 2015), it is notable that many staffers within RTCs have not even heard of practicing more family-oriented treatment interventions (Brown et al, 2010). Placing a child in residential treatment might help decrease the burden of treatment on families; however, if RTCs do not integrate families successfully into treatment might threaten the identity of the parent. Because residential treatment involves taking over the primary care of a child, parents must also locate themselves in relation to the institutional structures and practices. RTCs often relegate parents to roles of support, which, if parents struggle to perform this function, can lead to parental feelings of powerlessness or fatigue (Honkasilta et al., 2015). Although RTCs might introduce new 
uncertainties and struggles for parents, they are nonetheless important resources to help alleviate the load that accompanies a child with a mental illness or issues of behavioral health.

\section{Mental (Un)Health and Family Stigma}

In general, families with children with emotional and behavioral disorders tend to have scant resources when it comes to social support and family income (Brannan \& Hefflinger, 2001; Duchovic et al., 2009). Research has also shown that children with psychiatric disorders often have parents who face challenges of anxiety, depression, and substance abuse, and partner violence (Leschied et al., 2006). These factors complicate a parent's ability either to provide support for their child or to seek professional help.

Parents facing the demands of caring for a child with a behavioral or mental disorder report feelings of worry, guilt, sadness, fatigue, embarrassment, resentment, anger, and incompetence (Brannan \& Hefflinger, 2001; Preyde, et al., 2015). Indeed, a child's mental illness is often a disruption to the family system. Severe emotional or behavioral disorders can lead to a family's inability to adapt to distressing circumstances, a phenomenon also known as family disruption (Tahhan et al., 2010). Effects for families of children who have a severe emotional disorder can range from mild disruption, if there is assistance available to the families, to extreme distress (Rosenzweig et al., 2002). Families experiencing extreme distress report that the severity of their child's disorder, the self-perceived inability of the family to minimize distress, and the inadequate coordination among service providers exacerbates the family disruption (Yatchmenoff et al., 2004). Considering how youth in residential treatment centers often have a multitude of emotional and behavioral disorders (Connor et al., 2004), it can be presumed that their parents also experience disruption and stress, especially prior to enlisting the help of an RTC. 
Beyond the disruption of family, a child's mental health or issue of behavioral health can cause families to be rejected or shunned by the community. The disapproval or rejection of an attribute by society, or stigma (Bos et al., 2013), can lead others to dehumanize or antagonize individuals who are perceived to violate societal norms (Goffman, 1963). Despite not carrying the "mark" of mental illness themselves, families can suffer from something that Goffman (1963) called courtesy stigma by associating or being associated with individuals with mental illness. For example, in their review of literature concerning the stigma encountered by family members of individuals with mental illness, Corrigan and Miller (2004) found that Western culture associates parents with their child's mental illness in three ways: First, some people believe that parents cause their child's issues of mental health because of bad parenting or abuse; second, there is a notion that parents worsen or contribute to their child's issues of mental health because they fail to find adequate help or support the prescribed treatment for their child; and finally, others see parents with issues of mental health as having contaminated their children.

Corrigan and Miller (2004) also found that families can suffer stigma vicariously when they see the shame and isolation that a loved one is experiencing due to their issues of mental health. The way that society treats an individual with poor mental health can cause their family members to view their family as flawed or bad (Liegghio, 2017). In some cases, stigma can even inhibit a parent's ability to participate in their child's own treatment. In one qualitative study, parents described feeling that mental health professionals and social workers might see parents as part of the problem and subsequently ignore their input (Van Der Sanden et al., 2015). Despite a parent's best efforts to help their child, their child's mental health often makes it impossible not to violate the cultural ideals of "good parenting" (Corrigan \& Miller, 2004; Hays, 1996). 


\section{Disrupted Narratives of Parenting}

Although parenting performances are nuanced and varied, there are cultural narratives that constrain parents to hold certain values and behave in particular ways to be considered a "good parent" (Henderson et al., 2016). For example, mothers might refrain from voicing their displeasure with mothering and, instead, choose to communicatively frame motherhood as completely fulfilling to conform with dominant ideals of motherhood (Scharp \& Thomas, 2017). In her seminal work, The Cultural Contradictions of Motherhood, Hays (1996) identified the ideology of intensive mothering, a potentially marginalizing discourse which mothers and Western society often celebrate. Intensive mothering includes three beliefs: The mother should take the central role in childrearing; the mother should put the child's needs above her own; and the mother should view her children as priceless and thus no sacrifice of time, money, or energy is too great. Because of these beliefs, the idea that a mother could intentionally give up the caretaking of their child could be a severe violation of the cultural norms that inform parenting (Scharp \& Thomas, 2017).

The violation or potential violation of cultural expectations of parenting can discourage parents from seeking out support. Indeed, Thomas et al. (2014) found that women with postpartum depression often did not seek help or treatment because they felt ashamed that they had

failed as a mother. Similarly, parents might not place their child in residential treatment for fear that they would be seen as bad parents (Sayal et al., 2010). This is especially interesting when one considers how the ideology of intensive mothering encourages mothers to seek out child development professionals and implement their counsel (Hays, 1996). Taken together, this body of literature suggests that there might be a socially constructed limit to acceptable professional involvement in childrearing in which professional help is encouraged until it replaces mothers as 
the central caretaker. In other words, to protect a good mothering identity that is internally and culturally accepted, mothers might refrain from seeking professional help when it appears to take the child out of the home.

Traditionally for fathers, helping with childcare is seen as a supplemental or auxiliary function to the mother's role (Frascarolo et al., 2005; Lupton \& Barclay, 1997). However, discourses on fatherhood are starting to shift (Stevens, 2015). Although research suggests that men still primarily see their role as the breadwinner for the family (Miller, 2011), they also acknowledge that participating in child-rearing (whether equal to or partial with women) has become an expected and defining task of fatherhood (Miller, 2011; Stevens, 2015). However, fathers might feel caught between their roles as both a breadwinner and an involved father, as one participant in Duckworth and Buzzanell's (2009) study describes, "Work-family balance means providing ... spending enough time at work that my wife doesn't have to worry about money and spending enough time at home that my children will appreciate me ... as a father" (p. 564). Fathers might see that to perform the identity of a good father, they must achieve a worklife balance, meaning they work enough to provide for familial needs, while also reserving time to spend connecting with their child and taking care of emotional needs. Fathers of children with severe issues of mental and behavioral health might feel that they can still perform the role of breadwinner (providing the financial means that make such an intervention possible) but might struggle to feel they are as engaged with their child as fatherhood demands. Because issues of mental, emotional, and behavioral health often persist despite therapy and residential treatment (Preyde et al., 2009), fathers of children who suffer with severe issues of mental health might also feel that they have failed (or continuously fail) in their role as the solver of problems (Duckworth \& Buzzanell, 2009). Overall, both fathers and mothers are held accountable for the 
physical, emotional, and mental nurturing of their children. As such, it makes sense that a child who is physically, emotionally, and/or mentally unhealthy, and thus resides in an RTC, represents a deviation from or disruption in the culturally expected relationship and life course narrative about parents and children. Parents who experience this deviation from the norm might receive harsh critiques of their parenting from patient-care providers and network members that challenge their parenting-style or even their very identity as parents.

\section{Nature Versus Nurture}

Perhaps at the core of the discourses on parenting is the belief that parents and parenting style are key determinants of child development. Parents see their child-rearing style as a crucial aspect of their children's academic, social, and personality outcomes (Himelstein et al., 199; Respler-Herman et al., 2012) Social research on parents and child development also revolve around the narrative that parents play a primary role in the behavioral, emotional, and mental development of children (Kaul, 2019; Schriffin, 2014; Singh, 2017). Parents are expected to socialize their children to behave in ways that conform with society and help them reach their potential (Richards, 2018). Research on parenting styles emphasizes the ways in which a parent's approach to interactions with their child(ren) can influence the child(ren)'s self-esteem as well as lead to other mental health outcomes (Singh, 2017). Scholars of attachment theory often attribute the early interactions of parents with their children to a myriad of outcomes such as romantic relationship interaction (Shi, 2003), personality disorders (Levy et al., 2015), and destructive or aggressive behaviors (Mirzaaghasi, 2019). Even studies such as Kochanska et al.'s (2019) article on early parent-child interactions, which acknowledge the biological influence on children's behavioral outcomes, still place parents and their responses to their children as the prime determiner of child behavioral outcomes. 
However, there is a growing skepticism of this narrative of parental influence; for instance, Sherlock and Zietch (2018) point out that many studies on attachment might have confounding factors such as genetics which, when ignored, lead scholars to attribute a child's behavioral outcomes erroneously to parenting style. Barlow (2018) argues that although nature and nurture should not be seen as a dichotomy, greater emphasis should be placed on how genes predict traits and developmental outcomes, rather than environment and parenting style. In other words, although parents by definition play an important role in the lives of their children, researchers and the public might misattribute undesirable child outcomes to poor parenting. The false attribution of a child's problematic behavior or health issues to poor or inadequate parenting is a source of marginalization for parents of children with chronic and/or severe issues of mental or behavioral health and can lead parents to feel ambivalent about their role and execution of parenting (Corrigan \& Miller, 2004; Van Der Sanden et al., 2015).

\section{Parental Ambivalence}

Familial relationships and roles are not performed in isolation from the world around them, but instead shape and are shaped by cultural narratives (Connidis, 2010). Indeed, because of these narratives, parents might feel that despite enlisting every resource to help their child, they still are at fault for their child's behavior or health, thus complicating their ability to communicatively legitimize their parenting to others. Simply put, parents of children with severe mental health issues might not be able to perform good parenting in a culture that measures parents by the outcome of their children. Connidis (2010) called for the study of sociological ambivalence, or "how social structural forces create contradictions and conflicts that are made manifest in the social interactions of family life and must be worked out in family members' encounters with one another" (p. 140). Parents might experience sociological ambivalence as 
they struggle to navigate cultural expectations of good parenting (communicated to them by others and even themselves), while also incurring cultural blame for their child's mental, emotional, or behavioral health. Parents of children in residential treatment face many expectations, judgements, and contradictions concerning their role as a parent and must work to legitimize their experience and enactment of parenting.

In their effort to traverse the many contradictory narratives of parenting, parents might also perceive residential treatment as a threat to their own autonomy and legitimacy as a parent (Goldberg, 1991). Communication research suggests that once an individual enters the role of parent, it becomes a permanent part of their identity, even if the performance of the role differs from the cultural ideal (Scharp \& Thomas, 2018). Severe emotional and behavioral disorders in children can result in disruptive behavior that parents might feel powerless to change (such as ADHD or oppositional defiance disorder), preventing parents from feeling competent in their ability to parent (Jones \& Prinz, 2005; Preyde, et al, 2015). In light of the cultural (e.g., violating expectations of motherhood, fatherhood, and child development, as discussed) and relational (e.g., feelings of incompetence or uncertainty regarding parental responsibilities when a parent is no longer the primary caretaker of their child, as stated) ambivalence surrounding RTC experiences, the present study engages an ambivalence and meaning-making focused theory of communication and relationships: relational dialectics theory (see Baxter, 2011).

\section{Theoretical Framework: Relational Dialectics Theory (RDT)}

Although some scholars posit that culture is best observed through the averages and commonalities of experience within a given geographical area or community (Minkov \& Hostede, 2012), Becker (1999) argues that studying the disruption of ideals or expectations can illuminate hidden structures of order within the individual's culture. It is for this reason that 
individual narratives can prove to be a useful tool of inquiry. Narratives are stories that include a sequential storyline, specific characters, and the settings in which events occur (Riessman, 2007). Rather than focus on small, in-the-moment stories that might more accurately relate the details of events, Freeman (2006) argues that, through big stories, or narrative reflections, individuals can structure stories to create or highlight overall meanings and insight. Through their performance, narratives also identify which meanings do and do not matter (Langellier \& Peterson, 2004). Western culture compels individuals to describe their lives with linearity, or the idea that life follows a predictable path of cause and effect towards growth or failure. It is when personal experience deviates from these predictable paths that narratives have the potential to highlight discourses of normalcy and morality (or dominant discourses) and to (re)inscribe discursive lines to include, legitimize, and justify themselves, their actions, and their experiences that might be divergent with cultural expectations (Becker, 1999). Analyzing how individuals respond to and make sense of disruption can promote understanding of the underlying cultural values that motivate and constrain the ways in which individuals act and think. It is for this purpose that this study employs a narrative framework to interview participants.

Similar to the epistemological value that Becker (1999) and Freeman (2006) find in narratives, RDT, developed by Baxter and Montgomery (1996) and refined by Baxter (2011), positions utterances as the object of inquiry rather than the individual who utters them. This is an important clarification within the theory, because, as Baxter notes in her book, early application of RDT was oriented towards analyzing how certain individuals or personal relationships located themselves along the spectrum of discursive tensions (e.g., closeness and autonomy), rather than focusing on how individuals and their relationships are sites of discursive struggle. Instead of attending to the dialectics within relationships, Baxter explains that RDT's purpose is instead to 
explore the relationships of dialectics through an individual's utterances. Therefore, RDT can be applied in order to analyze how utterances of one speaker can voice multiple discourses present within society.

Utterances, which can be contained in narratives, are units of speech that begin when the speaker starts speaking and end when another person speaks (Baxter, 2011). Grounded in Bakhtin's (1986) work on dialectics, RDT posits that utterances are innately connected to past and anticipated speech on a relational and socio-cultural level; this concept of connection is known as the utterance chain. In this way, utterances give voice to relational and cultural discourses (Suter \& Seurer, 2018). Indeed, Baxter defines discourses as "systems of meaning" (2011, p. 124); in other words, discourses are socially learned norms or beliefs about the world. For example, Scharp and Thomas (2017) sought to study the meaning of motherhood in the stories of mothers who experienced prenatal and postpartum depression. By using RDT to explore these narratives, they found that two discourses emerged: The Discourse of Sacrificing Blissful Moms, which encourages society to expect women to sacrifice themselves for motherhood and to instantaneously love their children; and the Discourse of Mothers as Whole People, which suggests that mothers can value themselves and that they might need time to love their children. When only one discourse is present in the talk surrounding a particular semantic object, a phenomenon also known as monologue, meaning is lost.

Scholars who use RDT propose that the presence of multiple, often contradictory, discourses is vital for meaning to exist-it is when discourses compete that meaning is made (Scharp \& Thomas, 2017). Although multiple discourses are essential to make meaning, they rarely compete on a fair playing field. Baxter (2011) conceptualizes this imbalance of power by labeling the more dominant discourses as centripetal forces (centered), and the weaker, or less 
accepted discourses, as centrifugal (on the margins, thus marginalized). This unending struggle for meaning is known as the unfinalizability of interplay.

Interplay, or how discourses interact, takes various forms: diachronic separation, where the centrifugal (less accepted) discourse becomes the centripetal (dominant) over time; synchronic interplay, where discourses coexist centripetally with varying degrees of acceptance (Baxter, 2004a); and finally, dialogic transformation, where discourses blend to form an entirely new, and often paradoxical, meaning (Baxter, 2004b).

These varying forms of interplay are not only vital to the theory but also to RDT's analytical procedure known as contrapuntal analysis. Scholars performing contrapuntal analysis seek to understand what meaning discourses construct for certain concepts. This is done first by unfolding the utterance; this gives context to the utterance by determining what the utterance is responding to and anticipating in response, that is, its relation to an utterance chain (Baxter, 2011). Next researchers try to identify the different types of interplay by locating themes, organizing them according to similarity into a larger discourse, and finally, observing how these discourses compete with each other (as further described in the Methods chapter of this manuscript).

\section{Overview of Present Study}

Taken together, research on the topic of parents of children in residential treatment demonstrates how the severe issues of mental/behavioral health of a child and the enrollment of this child in residential treatment disrupt cultural expectations and narratives regarding parenting and child-rearing. Such a disruption highlights the ambivalence surrounding RTCs and constrains parents to make sense of the disruption and themselves, potentially illuminating 
discourses that either marginalize or legitimize their experience. Thus, the present study seeks to answer the following research questions:

RQ1: What, if any, discourses animate the meaning of parenting from the perspective of parents who have or have had children in residential treatment?

RQ2: How, if at all, do these discourses interact to make meaning of parenting?

\section{Conclusion}

This literature review demonstrated that there are gaps in communication research regarding parental experiences of enrolling children in residential treatment that could highlight new understandings of parental discourses. By using RDT I hoped to illuminate such discursive formations and their interplay. The next chapter will explore the methods I will use to examine participant narratives. 


\section{CHAPTER III: METHODS}

To understand discourses of parenting voiced by parents who have enrolled a child in residential treatment, I employed a qualitative research design, particularly focused on eliciting personal narratives, to answer my research questions. According to Baxter (2011) the narrative is a communication genre that allows an individual to voice and respond to a multitude of viewpoints simultaneously. The narrative's ability to contain multiple interacting viewpoints make it a dialogically expansive artifact (Bakhtin, 1986), meaning that it allows for many potential meanings to emerge (Baxter, 2011). Similarly, individuals can create narratives to make sense of disruption, in turn highlighting discursive struggle (Baxter, 2011; Becker, 1999). Therefore, narratives offer an ideal tool to explore the experiences of parents who have or have had children in an RTC.

\section{Participants}

With Institutional Review Board approval, I recruited six participants who were (1) the parent of at least one child who is or has been in a residential treatment center for issues of mental or behavioral health (while under the age of 18) and (2) 18 years of age or older. Two participants identified as white fathers and four participants identified as white mothers. Participant ages ranged from 48 to 60 years of age. Four parents reported being biologically related to their child and two participants reported having adopted their child. At the time of their

first admittance to an RTC, children's ages ranged from nine to 17, with the duration of their stay ranging from three days to spanning the course of three years.

\section{Data Collection}

To recruit participants, I posted a recruitment call (see Appendix A) on various social media accounts. I also contacted participants from a prior study (having previously received their 
consent to do so). Finally, I employed snowball and convenience sampling. The low number of participants can most likely be attributed to recruiting during an international pandemic as well as the sensitive nature of the topic and the reluctance of parents to discuss events that might be associated with failed parenting.

Upon recruitment, participants filled out a demographic questionnaire (see Appendix C). After receiving their demographic questionnaire, I interviewed participants using a narrative interview framework. Instead of conducting a heavily structured interview, I employed a semistructured protocol (see Appendix D) to prompt parents to tell their story of having a child in residential treatment, letting their story be the principal driver of the interview (Langellier, 1989; Lindlof \& Taylor, 2017). At the beginning of the interview, I asked participants to think of themselves as an author of a novel and to start from where they believe their story began concerning enrolling their child in residential treatment (see Scharp \& McLaren, 2018). As the story progressed, I asked further prompts to allow participants to elaborate on their experience (see McCracken, 1988), especially concerning their own beliefs about parenting. The mainline of questioning addressed what good parenting meant to participants. I also inquired as to how they responded to parenting critiques or affirmations that came from members of their network.

To ensure prolonged exposure and persistent exploration (Lincoln \& Guba, 1985) in this context, each interview lasted on average 55 minutes. After interviews were conducted, I transcribed each recording verbatim, removing any identifying information and replacing proper names with pseudonyms to protect participants' confidentiality. Transcription yielded 120 pages of double-spaced text. 


\section{Data Analysis}

To answer the research questions: (1) what, if any, discourses animate the meaning of parenting from the perspective of parents who have or have had children in residential treatment?

(2) how, if at all, do these discourses interact to make meaning of parenting? I employed Baxter's (2011) contrapuntal analysis. To this end, Braun and Clarke's (2006) six step process of thematic analyses was used to identify themes that answer the analytical question, "What is parenting?" To do this, I first read the data to familiarize myself with the holistic themes of each narrative. On my second reading of the data, I took notes on codes, themes, and contextual phenomena. Following this note taking, I grouped and re-grouped codes into inductively derived themes, according to the overarching themes that were present in them. After all codes coalesced into themes, I reviewed the themes, asking sensitizing questions such as, "What does a listener need to know in order to render this textual segment intelligible?" to see how themes formed discourses (Baxter, 2011, p. 159). After this process, I named and defined discourses, subsequently locating exemplars that captured the spirit of the emergent discourses.

After identifying the discourses that animated the meaning of parenting (RQ1), I then engage in the second component of contrapuntal analysis: unfolding the utterance, which allows the researcher to see power differential and struggle between the emergent discourses. To unfold utterances, I asked, "What does this textual segment respond to or anticipate?” (Baxter, 2011; Scharp \& Thomas, 2018). While unfolding the utterances in my data, I also looked for intrautterance competition which suggests the level of discursive interplay between the discourses identified in the data, specifically diachronic separation, synchronic interplay, and discursive transformations. Diachronic separation refers to when the dominance of a discourse changes over 
time such as a participant saying: "I used to think parenting meant , but now I think parenting means ___ " (see Baxter, 2011). Baxter states that synchronic interplay occurs when multiple discourses co-occur in the same moment in time. Synchronic interplay takes the form of negating, countering, or entertaining (Scharp \& Thomas, 2016). Negating occurs when a narrative rebuts a discourse directly or indirectly: "parenting is NOT ." Countering within narratives replaces the discourse that one might expect with another. Countering in narratives is often marked by words such as "but" or "even," such as: "I love being with my kid, but I need to take time for myself." Finally, entertaining refers to when a narrative centers one discourse, but suggests the validity of another or several other discourse(s): "I parent by being deeply involved with my child, but I know that some good parents give their kid more space." To find discursive transformations, I reviewed participant narratives to identify moments where utterances positioned discourses as compatible. After this process, I located exemplars that represent discursive themes and the different ways that the emergent discourses interacted to create meaning.

To ensure the credibility and trustworthiness of the data, I engaged in four methods of verification. First, I kept an audit trail, meaning that I logged and stored all decisions regarding the research process. Second, I performed exemplar identification, which involved substantiating the results with evocative quotes from the data. Third, I sent a copy of my findings to participants of my study, to ensure their representative accuracy (Lincoln \& Guba, 1985). Finally, I looked for recurrence (i.e., similar themes occurring across the data), repetition (i.e., specific words or phrases repeated across the data), and forcefulness (i.e, emphatic expression of participants) to ensure the validity of my data( Owen, 1984). In conclusion, an analysis of qualifying participant interviews using relational dialectics theory (RDT) as a theoretical 
framework and contrapuntal analysis as an analytical procedure yielded two different discourses of parenting. 


\section{CHAPTER IV: FINDINGS}

Through contrapuntal analysis, I found that two discourses animated the meaning of parenting from the perspective of parents who have had a child in residential treatment: the Discourse of Demanding Parenting Ideals and the Discourse of Realistic Best Effort. I describe below the themes that compose these discourses. After exploring the dimensions of each discourse, I will then describe the discursive interplay that occurred within participants' narratives.

\section{Discourse of Demanding Parenting Ideals}

The Discourse of Demanding Parenting Ideals (DDPI) invokes the cultural assumptions that parents have an ongoing obligation to become ideal parents. In practice, this means that parents do whatever is necessary to ensure their children are successful. The DDPI was identified as the dominant discourse as it held similarities with other dominant parental discourses and participants positioned it as the common understanding of parenting. The DDPI consists of two themes: limitless sacrifice and complete responsibility.

\section{Parents Sacrifice Without Limits}

The DDPI dictates that parents expend every effort and resource for the benefit of their children. According to the DDPI, at its simplest, parenting is providing for a child's needs. As Dayna, a mother who adopted her son from an abusive home when he was a toddler, explains, "I think a good parent is one who provides necessities, makes sure their child is physically and emotionally safe and healthy." However, despite this simple description of parenting, participants often described how ideal parents placed the needs of their children above their own desires. As Brandon, whose son struggled with attention, attachment, and sexual behaviors from an early age, describes, “The parents I feel need to do better are the ones who aren't providing for 
their family or they're looking to their own pleasures rather than the needs of their family." According to Brandon, it is not enough that a child's needs are taken care of, but according to the DDPI, good parents must put the needs of their children first. This hierarchy of needs leads parents make many sacrifices to provide for the physical and emotional well-being of their kids. Some participants discussed how efforts to be an ideal parent demanded an incredible amount of energy and time that even caused some participants to question their desire to live. Dayna states:

I wanted to be dead. A lot of the time I didn't want to wake up in the morning. I was so exhausted of trying to help him and parent. And so, I carried the shame of, "I am not good enough parent" and yet that's all I did with my time was tried to parent my son. In her statement, Dayna hints that the failure to be an ideal parent completely disqualified her from being a parent and therefore, took away her purpose for living. Like other participants, Dayna also describes how, no matter the amount of time, money, energy, and other resources spent, if the needs of their child were not met, the parent had failed. The DDPI also caused an extreme amount of doubt and inner turmoil when parents discussed how addressing the extreme needs of one child could impede a parent's ability to meet the needs of their other children as Arthur, the father of three kids, one of whom struggled with severe behavioral issues, explains: I look back and I'm like, was I a terrible parent? But at the time I was doing what a quotation marks, "normal parent would do." But I couldn't. I couldn't do normal parenting. So my parenting became skewed. I was treating the two kids one way and the other kid another way...So it went from, "This is what normal parents do" to adapting to what I had, I guess. Which wasn't fair to the well-behaved kids. 
Arthur implies with his narrative that "normal parenting" is sacrificing and providing equally for every child a parent has. These exemplars emphasize the DDPI's narrative that no parent's sacrifice is too great for the benefit of their children. When a parent is unable to meet the needs of any of their children, violating the DDPI's standard of parenting, they question their own ability to parent.

\section{Parents are Completely Responsible}

In conjunction with providing for a child's every need, the DDPI also places parents as the primary contributor to their child's failure or success. Arthur describes this phenomenon saying, "You think of parenting as, you know, we teach them right and wrong...the kid learns and everybody's happy." However, despite Arthur firmly delineating the roles of parents as teachers and children as learners, parents are at fault when a child fails to behave. When another participant, Abigail, felt that others were judging her based on her son's behavior, she reasoned: I think a lot of the people felt like it was the parents' fault, that, if only we were more strict or something, they wouldn't be having these problems, and I felt a lot of guilt. I felt like I was doing everything I could.

Abigail explains that when a child fails to perform the way they should, others attribute it to the parents lacking something. Similar to Abigail's experience, participants expressed that network members would give parenting suggestions, implying that participants lacked in discipline, love, patience, or consistency.

The narrative that parents are the key to a child's outcome is so strong within the DDPI that when children do not appear to be learning how to behave and live, parents also hold themselves accountable, even if they feel they have done everything they could, as Dayna explains: 
Every time we did an RTC, we felt like we had no choice, we begged him. We said, "If you'll just finish the sexual counseling, if you can just finish one program, you can come home," and he wouldn't do it. And yet, I still feel like I abandoned him, I still feel like I failed him, not the other way around. I don't sit here and tell you he failed me. I don't sit here and tell you the RTCs failed me, failed him. I say I failed and that makes me angry. And angry that I can't seem to get rid of that feeling of failure. Even though I did everything I could.

Not only does Dayna ground her failure through her son's inability to finish counseling, but she also refers to enrolling her son in a residential treatment center (RTC) as "abandonment" and cites it as another aspect of her failure as a parent. Dayna's phrasing suggests that, according to the DDPI, to raise good kids, parents need to be the primary caretaker of their children. Other participants were also deeply resistant to the idea of letting others participate in the raising of their child, as Abigail relates:

At one point, one organization was suggesting that we try something...called shared parenting, where basically, some people would step up to be like foster parents...And it didn't feel right to me, giving my son to some other people even if they are lovely. Abigail's reluctance to participate in shared parenting reifies the DDPI's idea that parents should be the sole caretakers of their children, regardless of the quality of the alternatives. This idea that children must be raised by their parents in their home created a great deal of uncertainty as the behavioral and mental health issues of participants became unsustainable. Even when participants' children were at an age where they would be expected to be more autonomous and live apart from their parents, participants still felt a sense of responsibility over their children's behavior. For example, Bethany felt uncertain as to when or if she could let her son live on his 
own, asking, “How much do you help? When do you let go? Can you let go?” Even at a time where Bethany felt that she had done all she could do and that her son was old enough to move out, she did not believe she could separate from her son if he needed her.

Corresponding with these beliefs about parents being the primary determinate of child outcomes, participants often expressed that good parenting was measured by good outcomes, or, in other words, "good, loving parents produce(s) good, loving kids...And a child who [fails] in society came from crappy parenting” (Dayna). Parents in the study repeatedly mentioned their expectations and need to be "enough" to help their child. This desire to ensure good outcomes made parenting an incessant and inescapable worry. Connie, a mother who admitted her son to an RTC in response to suicidal ideation, describes, "My parenting...just never ends. In my head it never turns off. From simple things to complicated things, to his health, to his future, to the decisions he's making now." The desire to be the "ideal parent" to her child made Connie agonize over every detail of her son's future, suggesting that part of the DDPI says ideal parents are responsible to prevent all harm and provide all possible opportunities.

Even when expressing that they were trying to help their kids overcome challenges where, in many cases, professional institutions had failed, participants still grappled with feelings that they should have been able to help. Arthur describes these feelings:

You have this sadness that you get. I guess you're kind of realizing that, "Our lives aren't going to be white picket fence with three kids in the yard playing happily." So there's a degree of depression and sadness that you're battling with. There's a degree of the failure and that you're not good enough. That's hard when you think you can manage something and do something and you finally decide, "I can't do this," you know, "it's not going to work..." 
Arthur envisions ideal parenting as producing a beautiful home and happy kids and his inability to reach that goal influenced his own self-efficacy as a parent.

In the end, some participants felt that, no matter what effort was expended for their child,

if the desired outcomes were not achieved, it was not enough and therefore a failure of parenting. This idea can be an inescapable struggle. Dayna spells this phenomenon out clearly:

I've always believed that I was an amazing mom, and the fact that I couldn't be enough... Even now, if I saw [my son], the first words out of my mouth would be "I'm sorry." And it doesn't matter that I did everything that you had to do. That belief that mental health comes down to the ability of your mother to bond with you and to nurture you, and to be there for you, is so pervasive in society and inside of me that I will forever feel like an apology.

In her excerpt, Dayna highlights the fact that this discourse exerts extreme internal and external stigma. Dayna also mentions that no matter what she did, she felt that she was to be held responsible for her son's undesired behavior. These exemplars suggest that, within the DDPI, parents (especially mothers) are so closely tied to their child's mental health that they are responsible to fix even the most severe mental health struggles.

Overall, the DDPI emphasizes the responsibilities of parenting (sacrifice and childrearing), but also forcefully ties parenting to outcomes (good parents produce good kids and the inverse). This dominant discourse encourages society to validate and invalidate parents and their efforts based on the behavior of their children.

\section{Discourse of Realistic Best Effort}

Where the DDPI largely contributes to societal ideals of parenting, it is not the only discourse that animates the meaning of what it means to parent. The Discourse of Realistic Best 
Effort (DRBE) resists the DDPI's definition of parenting by providing ways for individuals to validate their parenting without necessarily reaching the ideals of the DDPI. Connie encapsulates this discourse best when she says, "I think a good parent needs to be willing to understand what their child needs, but I think they also need to be realistic." Countering the DDPI's assumptions that good parenting equates to limitless sacrifice and complete responsibility, the DRBE suggests that parents can have limits and do not have to tie their parenting performance to the outcomes of their children. Utterances that make up this discourse coalesced into two themes: setting boundaries and acceptance.

\section{Parents Set Boundaries}

Unlike the DDPI, which tells parents that there is no limit to sacrifice and that children come first, the DRBE allows parents to express the importance of recognizing and fulfilling their own needs, even when it came at the cost of nurturing their own children. Arthur discusses his feelings about kicking his son out of his home:

Kicking him out at 18 was a relief. It wasn't saddening to me at all, it was a relief. Which, when I think back to it now is, you know, terrible. But that's what I had to do at the time. He was completely out of control at that point.

Even though Arthur still feels conflicted about kicking out his son, he frames the event as necessary to protect himself. Counter to the DDPI which demands that ideal parents put the needs of their child before their own, Arthur reflects that because there was no helping his son, he had to look to his own protection.

In cases that were less extreme than kicking a child out, participants discussed the importance of boundaries to preserve a sense of self outside of parenting. To this point, Dayna states, "I feel like good parenting does still include giving them opportunities. And it does 
include sacrifice, but not sacrifice of your whole sense of self. I believe more in boundaries than I once did." Although participants struggled to completely feel at ease putting their own needs first, they drew on discourses of autonomy within the DRBE to legitimate their personal needs and boundaries. Participants walked this line by framing self-care as a crucial supplement to good parenting. Abigail explains, "It's taking care of yourself so you're able to be a good parent. That's what good parenting is a about." Abigail's explanation is reminiscent of the flight instruction given to parents to put their own air mask on before helping their child. Parents used the DRBE to frame boundaries as a way of validating their own personhood and improving their parenting.

\section{Parents Accept}

Instead of the DDPI's narrative that the measure of a parent is the outcome of their children, the DRBE contests this connection and instructs parents to accept the constraints of circumstances, the behavior of their children, and personal limitations.

Parents accessed the DRBE to accept the situation and to adapt the best they could. When Brandon first adopted his son, he hoped that he could reverse the trauma that had happened to his son, but had to accept the restraints of his son's condition:

So, from the outset of parenting [my son], I had a goal of him being like my other four children. And a moment of awakening for me was when one of our counselors said, "You can't expect that much from a boy who has reactive attachment disorder and who has so many things in the nature aspect of his life. If we can just change his trajectory by a few degrees, that may be all that we can expect--we may not get him to turn 180 and go from being a crazy, defiant, overly rambunctious potential criminal to a perfect, upstanding member of society. Maybe the best we can expect is that [Son] will be able to hold down 
a job someday and stay out of jail.” At the beginning of our adoption, if I could have talked to myself and said, "Let's just change the trajectory, let's not turn him around," I think that there may have been less head-butting between me and him.

Although Brandon still hoped to influence his son, he recognizes that being able to accept the restraints of the situation would have eased his tension around parenting.

In a similar vein, participants engaged in talk in which they explained that good parenting was about accepting and connecting with their child rather than ensuring that no issues arose. Because of his experience with his son, Brandon reflects:

I'm much less worried about the things that I worried about back then: "Are we making a mess? Are we going to break something? Are we staying up past bedtime?” It's more about enjoying each other and creating those memories.

As Brandon expresses, some participants felt that, over time, they came to believe accepting and connecting with children was more important than worrying about who their child was or would become.

Finally, participants considered that in the face of daunting challenges, they would simply have to accept that they did the best they could and that parents cannot solve everything. Bethany speaks of releasing parental guilt:

Give yourself some slack. You know, you have that monkey mind where you get in bed and you can't fall asleep and you'll relive a decision, or you'll relive a situation. And you got to just kind of, say I did the best that I could. And if you've loved that child, you know, you did the best you could. 
To address her regrets or uncertainties about her parenting, Bethany tells herself that her affection for her child motivated her to do everything she could, regardless of outcome. Dayna expounds on this idea further, acknowledging the limits of her own abilities:

I think I've had to come to terms with the fact that doing my best doesn't mean my best wasn't good enough. It just wasn't enough. You can't save another human. Just like I can't be an Olympic athlete. I can't force [my son] to be an emotionally healthy person.

Instead of invalidating her own efforts as "not good enough," Dayna accepts that her son's needs required more than what she could give, and that she could not force him to be what she thought he should be.

In direct opposition to the DDPI, the DRBE allows parents to legitimize their parenting by accepting limits and setting personal boundaries. In other words, where the DDPI glorifies limitless sacrifice and blames parents for their children, the DRBE emphasizes limits to parental sacrifice and validates parents' best efforts. To clarify, the DRBE does not fix parenting or child outcomes. As Bethany expressed after accepting her child's behavior:

So, great. You've gotten to this spot of acceptance. Yeah. Good for you. Now, [just] because you accept it, doesn't mean it solves it, doesn't mean it's fixed. When you finally get a diagnosis for something...you still have to deal with the diagnosis.

As Bethany states, acceptance does not fix the issues of their child; however, what the DRBE encourages is that parents be evaluated as gift-givers rather than as investors. Wherein investors are evaluated by the outcome of investments, no matter the amount invested, gift-givers instead are validated by the efforts expended, not necessarily the outcome. With this mindset, parents can feel good about their efforts, instead of feeling that parenting is inaccessible to them. 
Abigail describes the process of parenting when one accepts that parenting is just doing the best that one can do:

It's adapting and learning and being flexible and trying to choose the right thing to do. I don't know if there's magic to it... It is special. It's the most difficult job I've ever done, but it's not rocket science.

Here, Abigail acknowledges that, within the DRBE, parenting is a special process of adaptation and effort, but not an impossible task. By framing parenting within the DRBE, Abigail can forsake reaching the magical ideals of parenting and thus separate her child's outcomes from her parenting. Brandon adds his perspective of parenting:

I had to embrace the fact that I was not a perfect parent, and that perfect parenting was probably an unachievable goal for anyone. Because it's a state of flux, where a perfect parent to one child at one time in their life is a completely different perfect parent to another child or the same child at another point in their life. And so [I had] to face the fact that, yeah, I had flaws, and that was okay.

Here, Brandon voices his effort to let go of his ideals of perfect parenting, acknowledging that it was unattainable even in the best circumstances, and that even good parenting shifts depending on the child, and the stage of that child. In the end, the overarching meaning that parents derived from the DRBE is that good parents are the ones who make their best effort with personal boundaries in place, not necessarily the ones who have figured out parenting or have good kids. Having established these discourses, I now turn to the interplay of the DDPI and the DRBE.

\section{Discursive Interplay}

Overall, the DDPI works to uphold the expectation that parents become ideal parents who sacrifice without end and evaluate themselves based on their children. Contrastingly, the DRBE 
resists this narrative by framing parenting as setting personal boundaries and acceptance. The collected narratives are rife with the interplay between these discourses as participants attempted to make sense of their failure to meet cultural ideals of parenting while simultaneously expending incredible amounts of energy to parent. This interplay took the form of diachronic separation, synchronic interplay, and discursive transformation (see Baxter, 2011).

\section{Diachronic Separation}

Diachronic separation, or the event where a marginal discourse decenters the dominant discourse over time, emerged both across and within utterances. Due to the narrative structure of the interview, participants at times enacted diachronic separation by using monologic utterances (utterances that contained only one discourse) that shifted in discursive emphasis over the course of the interview. For instance, at one point of his interview, Arthur relates a recent conversation he had with his son:

I told him, “[Son], it's your life now. You know, I'd like you to do better. I'd like you to be happy and proud of yourself. And if you are, okay then, it's your life."

In his conversation, Arthur is clearly letting go of responsibility, accepting his child's agency, and setting boundaries between his own life and his son's. However, later in the interview, when reflecting on what it means to be a good parent, Arthur says,

To see a good parent, is to see a parent that's not being selfish.... And you just do what your child needs so that that child can live the best life possible.

Here Arthur vocalizes the dominant discourse: Put the needs of the child first to ensure they have a good outcome. Meanings and centered discourses are constantly changing, even within an utterance. 
Diachronic separation often occurred within a single utterance. In her interview, Bethany describes how her beliefs changed over time:

I think, before I had children, I totally thought it was nurture over nature. [I was] convinced it was nurture over nature. I babysat kids, those kids could have been my kids; I could have easily adopted a child-that was my feeling. And upon having a child, nature is very strong. There is depression on my side of the family. But there's pretty severe depression on the paternal side. Not only the father, but the paternal grandmother. So, I kind of learned that nature really is quite a force.

Using the language of "nurture or nature" Bethany states that before she had a child of her own, she believed she could raise any kid, and that their outcome would be because of her. Upon having a child, she rethought this assumption and began to attribute familial mental health history (a constraint of the situation) to the outcome of her child rather than her own parenting. Diachronic separation also occurred as participants expressed how their experience had changed the way they evaluated other parents. Brandon describes this occurrence:

There's always that struggle or balance between nurture and nature. I thought that we could nurture the nature out of our son. And then the nature that he had developed before he came to our house was so strong, that it really wasn't my failure as a parent. As much as it was the exhaustion of my resources, my personal resources, and I was more empathetic to parents of kids that didn't seem well disciplined or didn't perform well in school... When [parents] had difficulties in their home, it wasn't because they weren't doing what they were supposed to do, it's just some kids are more challenging than others. 
Not only did Brandon's view of his own parenting change (also using the language of "nurture or nature"), but he also extends his insight to how he viewed other parents. The constant shifting of the central discourse over the course of an interview and within the utterances themselves is an easily observed example of the unfinalizability of interplay. Meanings never completely settle on one discourse but continue to struggle between the discourses that animate them.

\section{Synchronic Interplay}

Some utterances voiced both discourses as co-occurring (rather than shifting over time). Within these utterances, parents struggled to make meaning of parenting while feeling constrained and motivated by the dominant DDPI and the marginal DRBE. This struggle was negotiated through negating, entertaining, and countering.

\section{Negating}

Some participants called upon the dominant discourse in order to refute it. Reflecting on her daughters' examples of parenting, Dayna expresses:

I watch my own daughters put themselves first above their kids needs in some situations, and I'm just shocked, like, how you can do that? But I realize being a person should come before being a mother, and that my best parenting didn't come with my sacrifice. My best parenting came in my acceptance of my children.

Initially, Dayna voices her surprise that her daughters are, at times, able to put their needs above their children's, but upon further introspection she starts to negate the dominant discourse. First, she sets boundaries and separates her identity from motherhood: "Being a person should come before being a mother." Then she further affirms the DRBE by emphasizing that one should accept their children and disqualifies the DDPI by saying, "My best parenting didn't come with my sacrifice. My best parenting came in my acceptance of my children." Both phrases repudiate 
the DDPI's claim that parents must sacrifice and put their child's needs above their own.

Through negating, utterances both highlighted and fought the power and themes of the dominant DDPI. Rather than have their parenting dismissed by the criteria of the DDPI, parents used the DRBE as an empowering alternative to justify this resistance.

\section{Countering}

In other utterances, the dominant DDPI was brought up in order to be altered by the marginal DRBE. For instance, Brandon states, "I realized that even if I was as good as I could possibly be, that there would be times when it wasn't going to be enough." Here, Brandon recognizes the DDPI (i.e., parenting demands we do everything we can), but clarifies, there are times that good parenting is not good enough to help a child. Brandon does not completely refute the dominant discourse in his utterance but introduces the marginal DRBE to relabel himself as a good parent, despite the circumstances. Connie also counters the DDPI in her interview, talking about her son, "I found out even at the age of 14 and 15, I can't make things all better for him, you know, he has to do it himself." The word even implies that parents should be able to fix everything for their children, especially before adulthood. Despite only vaguely referring to the dominant discourse, Connie modifies it by saying that there are many circumstances where her son needs to fix his own problems because she does not have that ability. In many of these utterances, the DRBE was offered as a near caveat to the DDPI. In other words, parents should sacrifice and provide as much as they can, but they also need to understand the limits of their abilities.

\section{Entertaining}

Finally, synchronic interplay emerged in the form of entertaining. Entertaining occurred when parents considered both discourses as equally valid, but ultimately settled on one. As 
Bethany struggled to make sense of her son's behavior, she reflected on a conversation with her son:

I said it to [him] "I'm modeling for you. You live in a house that we do these things, we clean up after ourselves, we take care of each other." I don't understand why he doesn't get that. I don't know whether that's the mental illness or that's parenting. And so again, sometimes it's nice just to say it's mental. Let's just go with mental illness.

In her reflection, Bethany is conflicted as to whether her parenting or the mental health context is to blame for her child's behavior. According to the DDPI, she is to blame, but within the DRBE, she cannot be expected to overcome a mental illness. Entertaining acknowledges and privileges both discourses rather than forcing them to compete. In the end, she does not negate or counter the DDPI, she simply vocalizes both discourses, and settles on the DRBE, not because it is more legitimate, but because she prefers it to the alternative.

\section{Discursive Transformation}

Discursive transformation is the last form of discursive interplay that emerged from the utterances of participants. Instead of expressing discourses as diametrically opposed or incompatible, transformation occurred when utterances blended discourses together to form new meaning (Baxter, 2011). Within the data set, one discursive hybrid and one aesthetic moment emerged.

\section{Discursive Hybrid}

Discursive hybrids occurred when a participant was able to clearly acknowledge both the DDPI and DRBE, while also constructing a way in which these two discourses worked together to create new meaning. The discursive hybrid occurred when Connie discussed how she was trying to parent her son after learning that he was experimenting with marijuana. Instead of 
responding with harsh discipline, Connie discusses how she and her son's father decided against dramatic regulation if the experimentation did not appear to be interfering with other parts of his life. Connie expresses this hybrid by saying:

Some people would, I think, say that I'm a terrible parent, because I knowingly let my child do these things. But in my particular instance, I feel like the way that I am addressing it is being a good parent to MY son.

In this utterance, although Connie recognizes that the DDPI would demand that she control the behavior directly, she firmly states that her acceptance of her limits and her son allows her to exert more influence in the relationship. In other words, allowing her son to make his own choices allows her to participate in her son's choices. She elaborates on this hybrid:

I mean, I'm definitely his mother. And I let him make his own decisions. The reason why I'm able to let him make his own decisions...[is] because in a couple months, he's going to be 18. You know, and all of a sudden, that's off the table. I feel like the manner in which I'm giving him control to do whatever he wants is going to continue to encourage him to semi-ask, you know, or at least tell me, "Hey, Mom, I'm going out tonight. I'll be home by midnight."

Connie blends both discourses to imply that by accepting her son's agency and behavior she is still influencing her son and becoming an ideal parent for her child. Dayna referenced this possible hybrid when she said, "My best parenting came in my acceptance of my children"; however, it is within Connie's utterance that this phrase takes real shape. This transformation allows for the DDPI and the DRBE to exist in harmony. 


\section{Aesthetic Moment}

The second form of discursive transformation to occur was an aesthetic moment. This transformation is not a logical blending of discourses, but an emotive meld where discursive lines blurred. Arthur's narrative vocalized this aesthetic moment:

To be a good parent, you do whatever you have to do for your children, however it might hurt your ego, or however it might disrupt things, like your plan in life. You do whatever you need to do that's best for your family.

On its face, this utterance appears to almost monologically highlight the DDPI's theme of selfsacrifice, but when grounded in the context of the rest of Arthur's narrative, the meld emerges: To meet the needs of your children, you must sacrifice even your ideals of parenting. When Arthur talks about sacrificing ego and life plan, he is saying that he is sacrificing his aspiration to be an ideal parent and the "white picket fence with three kids in the yard playing happily" to be an ideal parent to his child. Although this meaning seems paradoxical, it seems to make sense emotionally and help Arthur make sense of his paradoxical experience of parenting.

\section{Conclusion}

In summary, the DDPI and the DRBE emerged as discourses that animated participant discussion of parenting. The dominant DDPI centered around sacrifice for children and responsibility for children and their outcomes. The more marginalized discourse, the DRBE, consisted of themes of personal boundary setting and acceptance. Participants used the DRBE to resist the DDPI over time (diachronic separation) and through several forms of synchronic interplay. Finally, one hybrid and one aesthetic moment emerged from the data in which 
participants positioned the DDPI and DRBE as complimentary rather than contradictory. In the following chapter, I expound on the theoretical and practical implications of these findings. 


\section{CHAPTER V: DISCUSSION}

The purpose of this study was to investigate the meaning of parenting in the narratives of parents who had enrolled their child in a residential treatment program for issues of mental or behavioral health. Through exploring six participant narratives using relational dialectics theory (RDT) as a theoretical lens and its corresponding analytical process, contrapuntal analysis, two discourses emerged. The dominant discourse, the DDPI, urged parents to strive for ideal parenting through sacrifice and responsibility. According to the DDPI, undesirable child outcomes were due to a failure in parenting performance. Narratives also provided an alternate, more marginal discourse, the DRBE, which resisted ideal parenting, and instead framed good parents as those who set boundaries for themselves and accepted themselves and their children.

\section{Theoretical and Practical Implications}

This study contributes to parenting and relational dialectics theory (RDT) literature. First, this study mirrors many of the propositions of the discourse of intensive mothering, while also extending some of its assumptions. Where Hays (1996) describes intensive mothering as mothers putting their child first, sacrificing everything, and playing a central role in child-rearing, the DDPI adds that the adequacy of these actions is measured by the outcome or behavior of the child. This addition means that when one is trying to legitimate their parenting, they must discursively navigate their actions and the mental health of their child.

Despite the discourse of intensive mothering's focus on mothers, the DDPI places both mother and fathers at the center of child outcomes; however, discursive constraints might look differently based on the role. For instance, although Arthur questioned his parenting due to his child's behavior, he was still able to justify kicking his son out of the house. In Brandon's case, 
when discussing a moment where a counselor suggested enrolling his son in residential treatment, he says:

It was a blow to my ego to think, "Okay, I'm going to be looked on as a parent that couldn't take care of his kid at home, and that he had to be sent away in order for us to live a normal life" and that wasn't it. What I really wanted was to find a place that could help him, whether it was in our home or away from our home

Brandon fears that others will challenge his parenting because he sent his son away, but internally understands that his son can receive help outside of the home. In both Arthur and Brandon's cases, although they still express inner struggle when sending a child away or having professionals take a bigger role in parenting their child, they are still able to justify the behavior. Mothers, on the other hand, struggled much more to justify this type of action within the DDPI: Abigail refused to participate in "shared parenting" and Dayna felt that she was abandoning her son by enrolling him in residential treatment. This difference in framing suggests that despite both mothers and fathers being responsible for the outcome of their children, within the DDPI the identity of motherhood might be more closely tied to raising kids within the home than that of fatherhood identities. Therefore, as was suggested earlier in this paper, these mothers could discursively justify enlisting professional help until it replaced their role as their child's central caretaker.

The findings of this study also provide new insights into discourses of fatherhood. Research on fatherhood often frames fathers as a fixer of problems (Duckworth \& Buzzanell, 2009) or a breadwinner for their family (Miller, 2011). In this study, fathers did see their duty as providing for their family and associated their parental failure in large part to their inability to fix 
their child. When fathers faced this failure, their definition of good parenting expanded the duties of fathers. For example, Brandon says:

Even though I provided physically for my family, emotionally, I was lacking in many senses and in that I valued the abilities of my wife. She could be there much more emotionally than I could many times. And admitting that that was a potential weakness of mine was a learning opportunity.

It is interesting that Brandon phrases his "emotional inability to be there" as a weakness and learning opportunity for himself. Within this utterance, the DDPI commands Brandon to reevaluate his fatherhood style because his child did not turn out the way he had hoped. He postulates that to be a better father, he could learn to participate more in the emotional work required to raise children. This phenomenon reflects the shifting narrative of modern fatherhood (Stevens, 2015) as gender roles begin to break down and more is expected out of parents in general.

Additionally, the discursive tension between ideal parenting and realistic parenting is reminiscent of the rational-idealized tension that Swidler (2001) discusses. Swidler frames idealized love within romantic relationships as a great motivator of heroic deeds. Indeed, love is seen to transform the individual into a being who is able to go to any length for another. Similarly, the narratives in this study reveal that within parenting, love is the power to transform oneself into one that could do everything a parent has to do. As Bethany states, "If you've loved that child, you know you did the best you could." Here Bethany suggests that a parent can know they did their best because loving one's child requires it. However, parenting narratives revealed that love is also the power to transform your child. Dayna relates: 
I was raised on Anne of Green Gables, Box Car Children, Jane Eyre. So many stories about orphans. The message is, over and over again, that if they just have love, if they just have love, if they just have love.

Although Dayna does not directly state the result of, "if they just have love," she implies that love should be enough to fix any child, regardless of background. In other words, where idealized love within romantic relationships means that one will do everything for another, prosaic love within parenting means that a parent will do everything and that it should be enough to change a child. According to Swidler, romantic partners commonly dismissed the lofty ideals of all-conquering and ever-lasting love in favor of a more rational framework where love comes gradually and is something to be worked towards. On the other hand, parents in this study had a difficult time forsaking the ideals of parenting in favor of acceptance and boundaries. Perhaps one reason that parents in this study struggled to escape ideals of parenting in favor of realistic expectations is not only because of the responsibility given to parents to influence their children, but also the discursive idea that parental bonds and love are instantaneous (Scharp \& Thomas, 2017). Considering this struggle, I suggest that family researchers consider how discursive assumptions and idealizations of parenting rooted in the DDPI might influence research projects to demand too much of parents. In other words, instead of primarily focusing on what behaviors and processes parents can improve or enact to achieve ideal child outcomes, I hope that family research moves toward exploring the high demands of parenting to inform the field and the public on what realistic parenting might look like.

One final theoretical implication emerged considering the aesthetic moment. Baxter (2011) claims that these moments capture the affective side of communication. She emphasizes that instead of achieving a synthesis of discourse where both discourses work together to achieve 
a final discursive transformation, aesthetic moments are affective in nature and communicate a temporary emotional wholeness. Arthur's aesthetic moment does not mean an end to the discursive struggle, as he continues to position and reposition the two discourses even after this moment; however, in the instant he utters this discursive transformation, discursive tensions ease and new meaning emerges: Parents sacrifice even their parenting ideals to be ideal parents. Although this paradox can be frustrating to think through logically, it offers comfort and soothing when felt emotionally. Baxter states that aesthetic moments occur within a relational interaction and establish a fleeting wholeness or unity of self and other; however, the aesthetic moment in our study suggests that such a moment can occur within oneself as well. Not only does this expand on previous understandings of how aesthetic moments occur, it also points towards the value of investigating the emotional function of meaning making within parenting roles.

In addition to theoretical implications, this study also holds practical applications. Participants in this study affirmed Corrigan and Miller's (2004) assertion that parents are blamed if children struggle with severe mental health. Not only did these assumptions appear in parents' self-reflection, but they also appeared when parents discussed how others critiqued their parenting or took it for granted. My study suggests that parents must consistently negotiate their parenting validity in response to discursively motivated challenges posed by romantic partners, immediate family members, educational staff, and even mental health professionals (e.g., participants reported that others would tell them to enact better discipline to fix their child's behavior). In accordance with the findings of this study, I posit that struggling parents might find it more helpful when their network members validate their parenting efforts, rather than offer parenting advice. 
Beyond spreading social awareness of this discursive struggle, I hope this study

encourages mental health professionals to find ways of incorporating this knowledge into their practice. Although mental health professionals can reduce parental strain in these contexts by helping parents manage their child's behavior, they might also consider assisting parents by pointing them towards finding ways of managing their parenting expectations and adapting to the reality of having a child with a chronic mental health condition. In other words, parents find benefit from learning to adapt to their child's chronic mental illness rather than from counseling that focuses only parental intervention trying to change their child's behavior. Mental health professionals might also find ways of validating parents by acknowledging the difficulty of the situation. Dayna describes her need of such validation:

The problems were just so bad at [the first residential treatment center] that you know, they would tell me how challenging he was. And it was weird because I didn't feel like I was getting emotional support from them. And yet they were saying how hard it was for them, I thought they were going to be the professionals, they were going to be the ones that could help him. And they were just saying how difficult he was [and] how impossible he was. And I thought people should be saying, "Wow, how did you do this for so many years by yourself?" But instead, I just felt over and over that I was failing. As Dayna suggests, RTCs and mental health care providers, despite their resources, might also struggle to handle a child's behavior; however, instead of defending their own struggles by faulting the other, mental health professionals and parents might find mutual validation by commiserating with one another. Furthermore, mental health care providers might also employ the DRBE or discursive transformations (i.e., the discursive hybrid: You can influence your child by giving them agency/letting go of control; or the aesthetic moment: Ideal parents sacrifice ideal 
parenting to help their child) to help struggling parents find ways to validate themselves as parents.

\section{Limitations and Future Directions}

Although I used several methods such as member checks and thematic redundancy to verify the validity of my findings regarding the discourses that inform the meaning of parenting, there are limitations. First, the demographic homogeneity and limited number of participants might not capture parenting discourses present in other cultures, socio-economic standing, and familial ties. Future research should address these concerns, as they might be able to expand upon the discourses of parenting. For example, studying parental discourse within same-sex couples might reveal new insights into how the DDPI might constrain parents differently when roles are not determined by gender. The parenting experiences that informed this study came from predominantly white parents who, through their own finances and insurance, were financially able to enroll their child in an RTC. Studies suggest that such a participant pool probably does not represent many parental experiences, as many children enrolled in an residential RTC come from a difficult economic background or are placed in an RTC by a court or a welfare-system. Despite the potential recruitment difficulty, I believe that it is of particular importance in future studies to attempt to study parenting narratives of parents whose child entered an RTC because of an external mandate, as these situations might illuminate how parents resist extreme marginalization.

Future research might also consider gathering a sample of parents whose children are currently attending an RTC. Although our sample criterion did not restrict such parents from participating, every participant in our study reported that their child was no longer in an RTC at the time of the interview. For this reason, the collected narratives tended towards a retrospective 
and holistic description of parenting experiences, describing parenting pre, post, and during treatment. By collecting parent narratives during their child's treatment, scholars might be able to elaborate more on the discursive struggle that was hinted at in this study when parents assess what parenting means when a non-adult child is outside of the home.

\section{Author Positioning}

To assess how my own experiences of research, family, and RTCs influence my scholarship, I offer the following reflection. First, this study mirrors my current program of study which primarily focuses on family disruption, meaning making, and health. These research themes guide my research due to my own experience with mental health in a personal and familial context. The idea to study parents in relation to RTCs emerged as I considered the experiences of my parents when they enrolled my adopted brother in residential treatment. Although my siblings and I struggled to make sense of his institutionalization ourselves, I realized that this event was even more upsetting and difficult to navigate for my parents. I witnessed both of my parents question the decision to enroll my brother in an RTC repeatedly; often mentioning their frustration with both themselves and the several residential treatment programs in which my brother was enrolled. My position as a child in a family that had enrolled another child in residential treatment influenced this project in a few ways. First, having a personal connection to parents who had institutionalized a child gave me the ability to sympathize with other parents in similar situations. My relationship with the context allowed me to believe and understand parents when they told me they had done everything they could to help their child; however, not being a parent myself, I was also able to have a moderate amount of distance from the intense and potentially triggering emotions that come when considering feelings of parental failure or inadequacy which might have hindered my ability to have 
prolonged exposure to the data. Because I am not currently a parent myself, I had several participants and other parents (who had not institutionalized a child) read over my findings to ensure that my descriptions and conclusions held both experiential and emotional accuracy. The feedback I received helped me refine my themes and use words that more adequately expressed the emotional component of parental discourses.

\section{Conclusion}

Despite there being much more research to be done on parents who have enrolled their child in an RTC, this study provides an important step forward towards understanding the discourses that these parents struggle to negotiate. By using RDT, not only was I able to illuminate these discourses, but I also identified ways in which these discourses interacted to explain parenting. By doing so, not only does this illuminate the experiences of these parents, but it also expands our understanding of parenting. Instead of only basing our measures of successful parenting on the outcomes of their children, this study suggests alternate ways of legitimizing parents who, despite their best efforts, have children who struggle to conform to or meet societal expectations. 


\section{REFERENCES}

Affronti, M. L., \& Levison-Johnson, J. (2009). The future of family engagement in residential care settings. Residential Treatment for Children \& Youth, 26, 257-304.

Bakhtin, M. M. (1986). The problem of speech genres. In C. Emerson \& M. Holquist (Eds.), Speech genres \& other late essays (V. W. McGee, Trans. pp. 60-102). Austin, TX: University of Texas Press. (Original work published in 1979)

Baker, A. J. L., Kurland, D., Curtis, P., Alexander, G., \& Papa-Lentini, C. (2007). Mental health and behavioral problems of youth in the child welfare system: Residential treatment centers compared to therapeutic foster care in the Odyssey Project population. Child Welfare, 86, 97-123.

Barlow, F. K. (2019). Nature vs. nurture is nonsense: On the necessity of an integrated genetic, social, developmental, and personality psychology. Australian Journal of Psychology, 71, 68-79. doi:10.1111/ajpy.12240

Baxter, L. A. (2004a). A tale of two voices: Relational dialectics theory. Journal of Family Communication, 4, 181-192.doi:10.1207/s15327698jfc0403\&4_5

Baxter, L. A. (2004b). Relationships as dialogues. Personal Relationships, 11, 1-22. doi:10.1111/j.1475-6811.2004.00068.x

Baxter, L. A. (2011). Voicing relationships. Thousand Oaks, CA: Sage.

Becker, G. (1999). Disrupted lives: How people create meaning in a chaotic world. Berkeley, CA: University of California Press.

Bettmann, J. E., \& Jasperson, R. A. (2009). Adolescents in Residential and Inpatient Treatment: A Review of the Outcome Literature. Child \& Youth Care Forum, 38, 161-183. doi:10.1007/s 10566-009-9073-y 
Bos, A. E. R., Pryor, J. B., Reeder, G. D., \& Stutterheim, S. E. (2013). Stigma: Advances in theory and research. Basic and Applied Social Psychology, 35, 1-9. doi:10.1080/01973533.2012.746147

Brannan, A. M., \& Hefflinger, C. A. (2001). Distinguishing caregiver strain from psychological distress: Modeling the relationships among child, family, and caregiver variables. Journal of Child and Family Studies, 10, 405-418. doi:10.1023/A:1016705306848

Braun, V., \& Clarke, V. (2006). Using thematic analysis in psychology. Qualitative Research in Psychology, 3, 77-101. doi:10.1191/1478088706qp063oa

Brown, J., Barrett, K., Ireys, H., Allen, K., Pires, S., \& Blau, G. (2010). Family-driven youthguided practices in residential treatment: findings from a national survey of residential treatment facilities. Residential Treatment for Children \& Youth, 27, 149-159. doi:10.1080/0886571X.2010.500137

Children's Mental Health Report [PDF file]. (2015). Child Mind Institute. Retrieved from https://childmind.org/downloads/2015 Children's Mental Health Report.pdf

Connidis, I. A. (2010). Family ties and aging (2 ${ }^{\text {nd }}$ ed.). Los Angeles: Pine Forge Press.

Connor, D. F., Doerfler, L. A., Toscano, P. F., Volungis, A. M., \& Steingard, R. J. (2004). Characteristics of children and adolescents admitted to a residential treatment center. Journal of Child and Family Studies, 13, 497-510. doi:10.1023/B:JCFS.0000044730.66750.57

Corrigan, P. W. \& Miller, F. E. (2004). Shame, blame, and contamination: A review of the impact of mental illness stigma on family members. Journal of Mental Health, 13, 537-548. doi:10.1080/09638230400017004 
Duchovic, C. A., Gerkensmeyer, J. E., \& Wu, J. (2009). Factors associated with parental distress. Journal of Child and Adolescent Psychiatric Nursing, 22, 40-48. doi:10.1111/j.17446171.2008.00168.x

Duckworth, J. D. \& Buzzanell, P. M. (2009). Constructing work-life balance and fatherhood: Men's framing of the meanings of both work and family. Communication Studies, 60, 558-573. doi: 10.1080/10510970903260392

Durrant, M. (1993). Residential treatment: A cooperative, competency-based approach to therapy and program design. New York, NY: W. W. Norton and Co., Inc.

Frascarolo, F., Zaouche-Gaudron,C., \& Favez, N. (2005). Variations in fathers' discourses on fatherhood and in family alliances during infancy. European Journal of Psychology of Education, 20, 185-199

Freeman, M. (2006). Life “on holiday"? In defense of big stories. Narrative Inquiry, 16, 131. doi:10.1075/ni.16.1.17fre

Frensch, K. M., \& Cameron, G. (2002). Treatment of choice or a last resort? A review of residential mental health placements for children and youth. Child \& Youth Care Forum, 31, 307-339. doi:1016826627406

Goffman, E. (1963). Stigma: Notes on the management of spoiled identity. Englewood Cliffs, NJ: Prentice-Hall

Goldberg, K. (1991). Family experiences of residential treatment. Journal of Child and Youth Care, 6, 1-6.

Hays, S. (1996). The cultural contradictions of motherhood. New Haven, CT: Yale University Press. 
Henderson, A., Harmon, S., \& Newman, H. (2016). The price mothers pay, even when they are not buying it: Mental health consequences of idealized motherhood. Sex Roles, 74, 512526. doi:10.1007/s11199-015-0534-5

Himelstein, S., Graham, S., \& Weiner, B. (1991). An attributional analysis of maternal beliefs about the importance of child-rearing practices. Child Development, 62, 301-310. doi: $10.2307 / 1131004$

Honkasilta, J., Vehkakoski, T., \& Vehmas, S. (2015). Power struggle, submission and partnership: Agency constructions of mothers of children with ADHD diagnosis in their narrated school involvement. Scandinavian Journal of Educational Research, 59, 674690. doi:10.1080/00313831.2014.965794

The Joint Commission (n.d.a). Orientation to the standards [Webinar]. The Joint Commission https://www.jointcommission.org/accreditation-and-certification/health-caresettings/behavioral-health-care/learn/ourstandards/\#64d5d314124d4b32b38ad6ea5dbf7c67_66962b0294f747f79fc797c6bd3c2f36

The Joint Commission (n.d.b). Why achieve accreditation. The Joint Commission. https://www.jointcommission.org/accreditation-and-certification/become-accredited/whyachieve-accreditation/

Jones, T. L., \& Prinz, R. J. (2005). Potential roles of parental self-efficacy in parent and child adjustment: A review. Clinical Psychology Review, 25, 341-363. doi:10.1016/j.cpr.2004.12.004

Kaul, K., Konantambigi, R., \& Anant, S. (2019). Child temperament and emotion socialization by parents and its influence on emotion regulation by children. Journal of Indian Association for Child \& Adolescent Mental Health, 15, 13-33. 
Kidder, L. H. (1981). Qualitative research and quasi-experimental frameworks. In B. Brewer, \& B. Collins (Eds.), Scientific inquiry and the social sciences (pp. 380-382). San Francisco, CA: Jossey-Bass.

Kochanska, G., Boldt, L. J., \& Goffin, K. C. (2019). Early relational experience: A foundation for the unfolding dynamics of parent-child socialization. Child Development Perspectives, 13, 41-47. doi:10.1111/cdep.12308

Langellier, K. M. (1989). Personal narratives: Perspectives on theory and research. Text and Performance Quarterly, 9, 243-276. doi:10.1080/10462938909365938

Langellier, K. M. \& Peterson, E. E. (2004). Storytelling in daily life. Temple University Press.

Leschied, A. W., Chiodo, D., Whitehead, P. C., \& Hurley, D. (2006). Association of poverty with child welfare service and child and family clinical outcomes. Community. Work and Family, 9, 29-46. doi:10.1080/13668800500420988

Levy, K. N., Johnson, B. N., Scala, J. W., Temes, C. M., \& Clouthier, T. L. (2015). An attachment theoretical framework for understanding personality disorders: Developmental, neuroscience, and psychotherapeutic considerations. Psychological Topics, 24, 91-112.

Lieberman, R. E. (2009). Foreword. Residential Treatment for Children \& Youth, 26, 223-225. doi:10.1080/13668800500420988

Liegghio, M. (2017). Not a good person: Family stigma of mental illness from the perspectives of young siblings. Child \& Family Social Work, 22, 1237-1245. doi:10.1111/cfs.12340

Lincoln, Y. S., \& Guba, E. G. (1985). Naturalistic inquiry. Newbury Park, CA: Sage.

Lindlof, T. R., \& Taylor, B. C. (2017). Qualitative communication research methods $\left(4^{\text {th }}\right.$ ed.). Thousand Oaks: Sage. 
Lupton, D., \& Barclay, L. (1997). Constructing fatherhood: Discourses and experiences. London: Sage.

Mark, T. L., \& Buck, J. A. (2006). Characteristics of U.S. youths with serious emotional disturbance: Data from the National Health Interview Survey. Psychiatric Services, 57, 1573-1578. doi:10.1176/ps.2006.57.11.1573

McCracken, G. (1988). The long interview. Newbury Park, CA: Sage.

Merikangas, K. R., Nakamura, E. F., \& Kessler, R. C. (2009). Epidemiology of mental disorders in children and adolescents. Dialogues in Clinical Neuroscience, 11, 7-20.

Miller, T. (2011). Falling back into gender? Men's narratives and practices around first-time fatherhood. Sociology, 45, 1094-1109. doi:10.1177/0038038511419180

Minkov, M., \& Hofstede, G. (2012). Is national culture a meaningful concept?: Cultural values delineate homogeneous national clusters of in-country regions. Cross-Cultural Research, 46, 133-159. doi:10.1177/1069397111427262

Mirzaaghasi, R., Behbudi, M., \& Fard, F. D. (2019). A comparative study on the predictive influence of family function and attachment style in foreseeing externalized behavioral problems in children. Journal of Fundamentals of Mental Health, 21, 296-304.

National Center for Health Statistics. (2020, June 15). Data and statistics on children's mental health. Centers for Disease Control and Prevention.

Owen, W. F. (1984). Interpretive themes in relational communication. Quarterly Journal of Speech, 70, 274-287. https://doi.org/10.1080/00335638409383697

Preyde, M., Adams, G., Cameron, G., \& Frensch, K. (2009). Outcomes of children participating in mental health residential and intensive family services: Preliminary findings. Residential Treatment for Children \& Youth, 26, 1-20. doi:10.1080/08865710802689555 
Preyde, M., Cameron, G., Frensch, K., \& Adams, G. (2011). Parent-child relationships and family functioning of children and youth discharged from residential mental health treatment or a home-based alternative. Residential Treatment for Children \& Youth, 28, 55-74. doi:10.1080/0886571X.2011.550171

Preyde, M., VanDonge, C., Carter, J., Lazure-Valconi, K., White, S., Ashbourne, G., Penney, R., Frensch, K., \& Cameron, G. (2015). Parents of youth in intensive mental health treatment: Associations between emotional and behavioral disorders and parental sense of competence. Child \& Adolescent Social Work Journal, 32, 317-327. doi:10.1007/s10560014-0375-Z

Respler-Herman, M., Mowder, B., Yasik, A., \& Shamah, R. (2012). Parenting beliefs, parental stress, and social support relationships. Journal of Child \& Family Studies, 21, 190-198. doi:10.1007/s10826-011-9462-3

Richards, N. (2018). Raising a child with respect. Journal of Applied Philosophy, 35, 90-104. doi:10.1111/japp.12239

Riessman, C. K. (2007) Narrative methods for the human sciences. Boston: Sage

Robst, J., Rohrer, L., Dollard, N., \& Armstrong, M. (2014). Family involvement in treatment among youth in residential facilities: Association with discharge to family-like setting and follow-up treatment. Journal of Emotional and Behavioral Disorders, 22, 1-7. doi:10.1177/1063426614523651

Rosenzweig, J. M., Brennan, E. M., \& Ogilivie, A. M. (2002). Work-family fit: Voices of parents of children with emotional and behavioral disorders. Social Work, 47, 415-424. doi:10.1093/sw/47.4.415 
Sayal, K., Tischler, V., Coope, C., Robotham, S., Ashworth, M., Day, C., Tylee, A., \& Simonoff, E. (2010). Parental help-seeking in primary care for child and adolescent mental health concerns: Qualitative study. British Journal of Psychiatry, 197, 476-481. doi:10.1192/bjp.bp.110.081448

Scharp, K. M., \& McLaren, R. M. (2018). Uncertainty issues and management in adult children's stories of their estrangement with their parents. Journal of Social \& Personal Relationships 35, 811-830. doi:10.1177/0265407517688097

Scharp, K. M., \& Thomas, L. J. (2017). “What would a loving mom do today?”: Exploring the meaning of motherhood in stories of pre-natal and post-partum depression. Journal of Family Communication, 17, 401-414. doi:10.1080/ 15267431.2017.1355803

Scharp K. M., \& Thomas, L. J. (2018). Making meaning of the parent-child relationship: A dialogic analysis of parent-initiated estrangement narratives. Journal of Family Communication, 18, 302-316. doi:10.1080/15267431.2018.1484747

Schiffrin, H. (2014). Positive psychology and attachment: Positive affect as a mediator of developmental outcomes. Journal of Child \& Family Studies, 23, 1062-1072. doi:10.1007/s10826-013-9763-9

Sherlock, J. M., \& Zietsch, B. P. (2018). Longitudinal relationships between parents' and children's behavior need not implicate the influence of parental behavior and may reflect genetics: Comment on Waldinger and Schulz (2016). Psychological Science, 29, 154157. doi: $10.1177 / 0956797617717041$

Shi, L. (2003). The association between adult attachment styles and conflict resolution in romantic relationships. American Journal of Family Therapy, 31, 143-157. doi:10.1080/01926180301120 
Singh, S. (2017). Parenting style in relation to children's mental health and self-esteem: A review of literature. Indian Journal of Health \& Wellbeing, 8, 1522-1527.

Stevens, E. (2015). Understanding discursive barriers to involved fatherhood: The case of Australian stay-at-home fathers. Journal of Family Studies, 21, 22-37. doi:10.1080/13229400.2015.1020989

Stroul, B. A., \& Friedman, R. M. (1996). The system of care concept and philosophy. In B. A. Stroul (Ed.), Children's mental health: Creating systems of care in a changing society (pp. 3-21). Baltimore, MD: Paul H. Brookes.

Sunseri, P. A. (2004). Family functioning and residential treatment outcomes. Residential Treatment for Children \& Youth, 22, 33-53. doi:10.1300/J007v22n01_03

Sunseri, P. A. (2020). Hidden figures: Is improving family functioning a key to better treatment outcomes for seriously mentally ill children? Residential Treatment for Children \& Youth, 37, 46-64. doi:10.1080/0886571X.2019.1589405

Suter, E., \& Seurer, L. (2018) Relational dialectics theory: Realizing the dialogic potential of family communication. In Braithwaite, D. O., Suter, E., \& Floyd, K., Engaging theories in family communication: Multiple perspectives (2nd ed.) (pp. 244-254). New York, NY: Routledge.

Swidler, A. (2001). Talk of love: How culture matters. Chicago, IL: The University of Chicago Press.

Tahhan, J., St Pierre, J., Stewart, S. L., Leschied, A. W., \& Cook, S. (2010). Families of children with serious emotional disorder: Maternal reports on the decision and impact of their child's placement in residential treatment. Residential Treatment for Children \& Youth, 27, 191-213. doi:10.1080/0886571X.2010.500956 
Thomas, L., Scharp, K. M., \& Paxman, C. G. (2014). Stories of postpartum depression: Exploring health constructs related to mothers' help-seeking behaviors. Women \& Health, 54, 373-387. doi:10.1080/03630242.2014.896442

Thomson, S., Hirshberg, D., \& Qiao, J. (2011). Outcomes for adolescent girls after long-term residential treatment. Residential Treatment for Children \& Youth, 28, 251-267. doi:10.1080/0886571X.2011.605051

Van Der Sanden, R. L. M., Bos, A. E. R., Stutterheim, S. E., Pryor, J. B. \& Kok, G. (2015). Stigma by association among family members of people with a mental illness: A qualitative analysis. Journal of Community \& Applied Social Psychology, 25, 400-417. doi:10.1002/cap.2221

Work Group on Healthcare Access and Economics (2010, June). Principles of care for treatment of children and adolescents with mental illnesses in residential treatment centers. https://www.aacap.org/App_Themes/AACAP/docs/clinical_practice_center/principles_of _care_for_children_in_residential_treatment_centers.pdf

Yatchmenoff, D. K., Koren, P. E., Friesen, B. J., Gordon, L. J., \& Kinney, R. F. (2004). Enrichment and stress in families caring for a child with a serious emotional disorder. Journal of Child and Family Studies, 7, 129-145. doi:10.1023/A:1022935014502

Yeheskel, A., Jekielek, A., Sandor, P. (2020). Taking up residence: A review of outcome studies examining residential treatment for youth with serious emotional and behavioural disorders. Children and Youth Services Review, 111, 1-16.

doi:10.1016/j.childyouth.2020.104842 


\section{APPENDIX A: PARTICIPANT RESEARCH CALL}

Are you a parent who is 18 years or older and who has enrolled a child in a residential treatment program? If so, we would love to hear about your experience. Under the direction of Dr. Lindsey Thomas, a faculty member in the School of Communication at ISU, I, Jared Worwood, a graduate student at ISU, am conducting a research study about the experiences of parents of have or have had children enrolled in a residential treatment program.

In order to participate in the present study, individuals must be: (1) the parent of at least one child who is or has been in a residential treatment center for issues of mental or behavioral health when they were younger than 18 years old and (2) 18 years of age or older. If you choose to participate, you will be asked a series of demographic questions and then then asked to discuss your experience having a child enrolled in a residential treatment program with an interviewer. The interview should take between 45 minutes to an hour. Participants will not be compensated for their participation.

I hope you will consider sharing your story with us and/or forwarding this announcement to other people you know who might be interested in sharing their experience.

If you have any questions about this study, or would like to participate, please contact Jared Worwood, at jvworw1@ilstu.edu (435) 359-8653 or Dr. Lindsey Thomas at 1jthom3@ilstu.edu or (309) 438-3671. 


\section{APPENDIX B: INFORMED CONSENT FORM}

\section{Consent Form: Parents of Children in a Residential Treatment Facility}

\section{Introduction}

You are invited to participate in a research study conducted by Dr. Lindsey Thomas, a faculty member at Illinois State University, and Jared Worwood, a graduate student at Illinois State University. The purpose of this research is to investigate the experiences of parents who have children that either have been or currently are in a residential treatment. To participate in this study, you must be: (1) the parent of at least one child who is or has been in a residential treatment center for issues of mental or behavioral health (while under the age of 18) and (2) 18 years of age or older.

\section{Procedures}

Your participation will involve being asked specific questions regarding your experience having a child in residential treatment, specifically, how this influenced your view on parenting and parenthood. Participation in the interview is expected to take 45 minutes to an hour. Interviews will be conducted over the phone, or via video chatting through Skype, Facetime, or other preferred platform.

\section{Benefits}

You may gain new insights into your experiences by participating in this study. This study will also provide insight for both residential treatment programs and practitioners that they can use to help better address the difficulties and stigma of their residents' families. It will also help researchers learn more about the experiences of parents of children in residential treatment and may help future individuals going through the same experience. 


\section{Confidentiality}

We will collect your information through audio recordings of your interview. This information will be securely stored on password-protected researchers' personal laptops. Upon completion of the interview, we will transcribe your recording and keep the transcript on a password-protected computer. The researchers will make every effort to ensure that the information you provide as part of this study remains confidential. Your identity will not be revealed in any publications, presentations, or reports resulting from this research study and all identifying cities and names of other individuals will also be changed to protect the confidentiality of the participant. The list of corresponding pseudonyms will be kept in the secure folder on the researchers' personal laptops. The pseudonym will be then used if any quotes or examples are pulled from the data and used in a presentation of the findings. Please also note that after the data has been deidentified, it may be used for other research projects.

We need to make you aware that in certain research studies, it is our legal and ethical responsibility to report situations of child abuse, child neglect, sexual violence, domestic violence, or any life-threatening situation of parties related to Illinois State University, illegal activity on the ISU campus, campus-controlled locations, or involving ISU students to appropriate authorities. However, you may not be affiliated with ISU (and thus this policy may not apply to you) and/or we are not seeking this type of information in our study nor will you be asked questions about these issues. But please be aware that if you share any of this type of information, we may be required to report it.

\section{Risks \& Seeking Help}

This is a minimal risk research study. That means that the risks of participating are no more 
likely or serious than those you encounter in everyday activities. You may feel discomfort sharing stories of an emotionally sensitive nature. Although we will make every effort maintain your confidentiality, if your information became accessible to others, you risk harm to your reputation and/or social standing due to the information you share. To minimize those risks and discomforts you have the right to refuse to answer any questions, and may withdraw from the study at any time. The stories or experiences you share are entirely up to you.

There are resources available to help you if you experience distress as part of your participation in this study. Please contact Illinois State University's Counseling Services at (309) 438-3655 if you are part of the ISU community. You may also contact PATH (Providing Access to Help) at 211 or 1-888-865-9903 or NAMI (National Alliance on Mental Health) at 1-800-950-6264 for help outside of the Illinois State University campus.

\section{Voluntary Participation \& Withdrawal}

Your participation in this research is completely voluntary. If you agree to participate now and change your mind later, you may withdraw at any time by simply telling the interviewer you would like to end your participation. If you choose to withdraw after we have already collected information about you, please contact one of the researchers and your information will be removed from the study and destroyed.

\section{IRB Review}

The Institutional Review Board (IRB) for the protection of human research participants at Illinois State University has reviewed and approved this study. If you have questions about the research study itself, please contact the Principal Investigator at (309) 438-3277 or aeott@ilstu.edu. If you have any questions about your rights as a participant, or if you feel you 
have been placed at risk, contact the Illinois State University Research Ethics \& Compliance Office at (309) 438-5527 or IRB@ilstu.edu.

By sending back a completed demographic form, you consent to participating in this study.

Dr. Lindsey Thomas

Principal Investigator

(309) 438-3671; 1jthom3@ilstu.edu

Jared Worwood

Graduate Student Investigator

jvworw1@ilstu.edu 


\section{APPENDIX C: DEMOGRAPHIC QUESTIONNAIRE \\ Demographic Information}

Please answer the following questions and return your answers to the researcher before your interview.

Please indicate your age:

Please indicate your gender identity or indicate that you choose not to identify.

Please indicate the ethnic/racial category(ies) that you most closely identify with. Check all that apply.

American Indian/Alaska Native
Asian/Pacific Islander
Black/African American
Hispanic
White, non-Hispanic
Other (please specify):
Choose not to identify

Please indicate which of the following best describes your relationship to your child.

Biological parent
Adoptive parent
Stepparent
Foster parent
De facto parent
Estranged parent
Other (please specify):

Please indicate which of the following best describes your child. My child is a current resident of a residential treatment facility. My child was a previous resident of a residential treatment facility. 
Please indicate for how long your child was/has your child been a resident of a residential treatment facility (if your child has stayed at multiple RTCs, indicate the composite amount of time).

Please indicate the age of your child when they first became a resident.

Please indicate your child's current age.

Please indicate how far from the residential treatment facility(ies) you did/do live during the time your child resides/resided there.

Same city

Same state, different city

Different state

Different country

Please indicate how many children you have (including the one who was or is in the residential treatment facility).

Please indicate the highest level of schooling that you have completed.

Less than high school diploma

High school diploma or GED

Trade School Certification

Some college, no degree

Associate's degree

Bachelor's degree

Master's degree

Professional degree (for instance, JD, MD)

Doctorate 
Please indicate your current marital status.

Single
Dating
Unmarried and living together with a romantic partner
Engaged
Married
Remarried
Divorced
Widowed
Other (please specify):

Thank you! 


\section{APPENDIX D: INTERVIEW PROTOCOL}

\section{Interview Protocol: Parents of children in a RTC (RDT/Support)}

Intro: Hello, my name is , I am a researcher affiliated with Illinois State

University. I am conducting this interview in order to explore the experiences of parents who have or have had children enrolled in a residential treatment center. Our interview today should not last more than an hour. Do you have any questions before we begin?

1.To begin the interview, I would like you to tell me the story of your experience being a parent of a child in residential treatment. I want you to think of it like a novel. There's no right way to tell your story and I want to hear about your story step by step. So, pretend that you are the author of the novel and you can edit the chapters that have already been written. You can also add or retell more stories. So, if you would like, begin where you think the story begins.

\section{[The following questions are to be asked at the interviewer's discretion throughout the narrative portion of the interview]}

- How did others respond to your child's behavior?

a. Were you ever implicated in these responses?

b. Did you address these responses? If so, how?

- How did you make the decision to place your child in residential treatment?

- Did you have any reservations during the process of placing your child in residential treatment? If so, how did you respond to them?

- What type of information, if any, did you share with others about your child's enrollment in a residential treatment program? How did you make decisions about whether to share this information?

- When you did tell others about your child's placement in an RTC or mental health, how would you explain it?

- How did people respond to your child's enrollment in a residential treatment program? 
- What was the role that played in supporting you and your child?
a. Family
b. Friends
c. The RTC(s)
d. Your child's school
e. The State

- Did give you the type of support you expected? Why or why not?
a. Family
b. Friends
c. The RTC(s)
d. Your child's school
e. The State

- What type of support did you find the most helpful (and from who)?

- Were there any points of your experience where you felt unsure or different about your parental role in your child's life or in other parts of your sense of self or identity? If so, what were those experiences and feelings and how did you respond to them?

- Has your experience changed the way you approach parenting? If so, how?

- What does "being a good parent" mean to you now?

- If you could go back in time and tell your younger self something regarding this experience, what would you say?

\section{[Ending the interview]}

- I'm wondering if you might reflect for one last moment about what this interview, here today, has been like for you. What were your thoughts and feelings during the interview? How do you think this interview has affected you? Do you have any other comments about the interview process?

- May I contact you with future studies that may involve children in RTCs?

Outro: Thank you for sharing your experiences with me. Your time and willingness to talk is appreciated. If you have any questions, please feel free to contact me at any time. 